\title{
The role of HOX genes in head and neck squamous cell carcinoma
}

$$
\text { Platais } \mathrm{C}^{1} \text {, Hakami } \mathrm{F}^{1} \text {, Darda } \mathrm{L}^{1} \text {, Lambert } \mathrm{DW}^{1} \text {, Morgan } \mathrm{R}^{2} \text {, Hunter } \mathrm{KD}^{1,3}
$$

${ }^{1}$ Unit of Oral and Maxillofacial Pathology, School of Clinical Dentistry, University of Sheffield, Sheffield, S10 2TA, UK

${ }^{2}$ Institute of Cancer Therapeutics, University of Bradford, Bradford, BD7 1DP, UK

${ }^{3}$ Department of Oral Pathology and Biology, University of Pretoria, Pretoria, South Africa

Short Title: HOX genes in Head and Neck Cancer

Address for correspondence:

Dr Keith D Hunter

Reader in Oral and Maxillofacial Pathology

School of Clinical Dentistry

University of Sheffield

Claremont Crescent

Sheffield, S10 2TA

Tel: 01142717956

Fax: 01142717894

Email: k.hunter@sheffield.ac.uk

Keywords:

Head and Neck Cancer, HNSCC, HOX genes, Homeobox. 


\begin{abstract}
Recent decades have witnessed the publication of numerous studies reporting alterations in the genome and transcriptome of head and neck squamous cell carcinoma (HNSCC). Currently, the utilisation of these alterations as biomarkers and targets for therapy are limited and new, useful molecular characteristics are being sought. Many of the published HNSCC gene expression profiles demonstrate alterations in the expression of HOX genes. These are a family of Homeobox containing genes which are involved in developmental patterning and morphogenesis in the embryo, and which are often aberrantly expressed in cancer. The 39 HOX genes found in the human genome are arranged in 4 paralogous groups at different chromosomal loci. These control a wide range of cellular processes, including proliferation and migration, which are relevant in the context of cancer development. In this review article we will outline the biology of HOX genes in relation to cancer and summarise the accumulating evidence for their role in the development of HNSCC and the possibility that they could be a therapeutic target in this malignancy. We will also identify areas where our current understanding is weak in order to focus future work and appraise the ongoing strategies for pharmacological intervention.
\end{abstract}


In 1894, William Bateson described structural variations and body part replacement/transformations in insects, and named this phenomenon "homeosis" (1). The discovery of gene mutations linked to homeosis continued and two homeotic gene complexes (HOM-C), which control Drosophila segmentation, were described $(2,3)$. Homeotic proteins encoded by the HOM-C genes were identified as transcription factors $(4,5)$, and for the majority of these their function is mediated by a highly conserved 180 base pair DNA sequence, the homeobox, which encodes a 60 amino acid long DNA-binding protein domain, known as the homeodomain (6). Many homeobox-containing genes have been identified in invertebrates and vertebrates, including humans $(6,7)$. The main functions of non-homeotic homeobox genes include determining cell fate and differentiation pathways, and regulating the required cell behaviour during morphogenesis, such as migration (8).

Homeobox genes have been grouped into different classes and families. The human genome is estimated to contain around 235 functional homeobox genes (9). The HOX genes are a specific family of Homeobox-containing genes contained within four genomic clusters: these clusters are named $A, B, C$, and $D$ and, based on sequence similarity, the genes are sorted into 13 paralogous groups with an equivalent position in each cluster. The genes are numbered in each cluster from 1 at the $3^{\prime}$ end to 13 at the $5^{\prime}$ end. When a paralogous group is absent from a cluster, the corresponding gene number is omitted (10). In humans, there are 39 HOX genes clustered on chromosomes $7 \mathrm{p} 15.3$, 17q21.3, 12q13.3, and 2q31 respectively (Figure 1) (11).

A number of associated molecular events are responsible for enhancement of homeodomain binding and specificity. Functional motifs contribute to homeodomain specificity by facilitating the interaction of HOX proteins with other transcription factors, such as PBX and MEIS $(12,13)$. HOX-PBX complexes have increased DNA binding affinity and specificity compared to HOX proteins alone (14, 15). With the aid of these co-factors, some HOX genes have distinct functions while many others appear to exhibit overlapping or redundant functions (16).

\section{Regulation of HOX gene expression and activity}

In development, the expression of HOX genes is highly organized along the antero-posterior axis in patterns termed spatial and temporal collinearity. In spatial collinearity, HOX genes toward the $3^{\prime}$ end of a cluster have a more anterior boundary of expression than those closer to the $5^{\prime}$ end. Thus, for example, the limit of HOXB1 expression is at the midbrain/hindbrain border, whilst that of HOXB9 is in the spinal cord. Temporal collinearity describes the correlation between the order and the timing of HOX gene expression during embryogenesis: early expression of $3^{\prime}$ genes during embryonic life versus the later expression of $5^{\prime}$ genes (17). In addition, HOX cluster genes exhibit "posterior prevalence", which is a functional dominance of posterior genes over their more anterior 

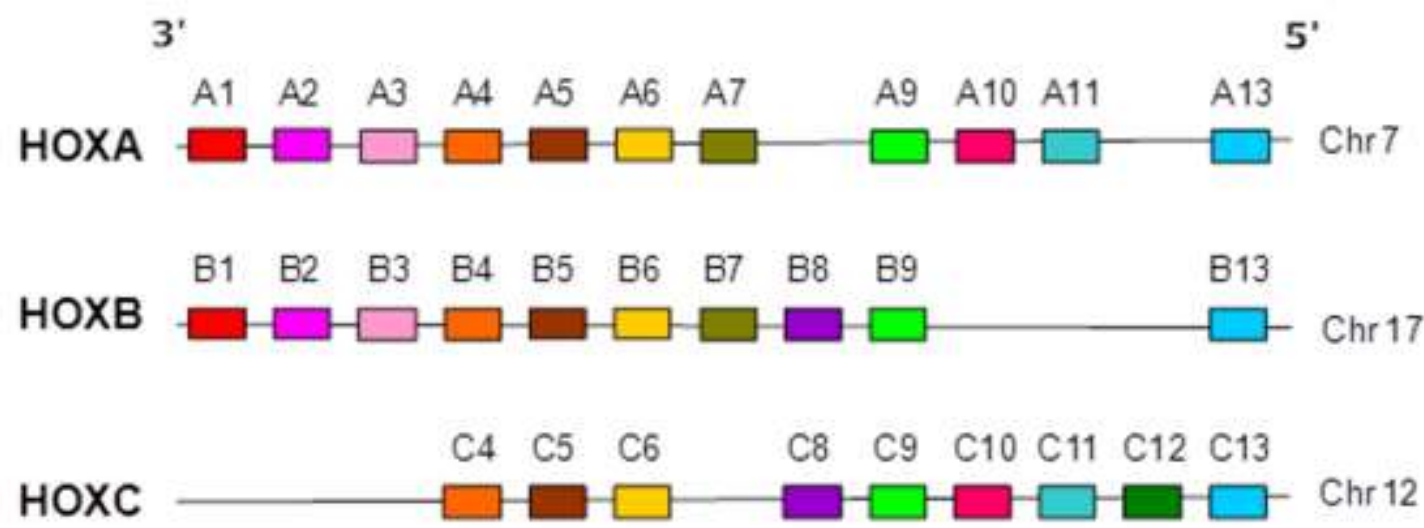

HOXD $\square$ D1 D3 D4 D8 D10 D11 D12 D13

Figure 1. Diagram of the arrangement of HOX genes by paralogous group (1-13) in 4 clusters (A-D), each at a different chromosomal location. 
neighbours (18). Other factors participate in the complex patterns of HOX gene expression and activation, including regulation during adulthood. These include hormones, such as oestrogen, progesterone (19-22) and retinoic acid (vitamin A) which is a key regulator of HOX gene expression during embryogenesis in a concentration-dependent manner (23-25).

There is also increasing interest in epigenetic control of HOX gene expression in the context of development and cancer. This includes co-ordinated changes in promoter methylation and histone modifications $(26,27)$. An overall screen of DNA methylation in oral cancer cells showed increased methylation at sites within the HOX clusters (28), and this was further explored in the HOXB cluster, with re-expression of HOXB4 after treatment with DNA-methyl-transferase inhibitors (29). These changes have been linked to alterations in the activity of polycomb repressive complexes (PRCs) that can control HOX gene expression (30).

The HOX clusters also contain a number of short and long non-coding RNA transcripts (Figure 2). Some of these, for example miR-10 and miR-196, have been extensively investigated both in development and cancer, and have widespread effects, including repressing the expression of a number of HOX genes (31-34). miR-10b represses HOXD10 expression in breast cancer, contributing to enhanced migration and invasion via RhoA/RhoC signalling (35), although this effect is not seen in HNSCC (36). There is also accumulating evidence that a number of long non-coding RNAs, such as HOTAIR, have pro-tumourigenic effects in many cancers including HNSCC (37), some of which may be mediated by alterations in HOX gene expression and activity. The regulatory mechanisms of the HOX loci miRNAs generally remain unclear, although we have shown that miR196a can be expressed in a polycistronic transcript that includes HOXB9 and possibly other B cluster genes (32), which may indicate a direct link between the altered expression of HOX genes and their corresponding microRNAs in cancer.

\section{HOX genes in human development}

It is widely accepted that during embryogenesis, HOX genes control the expression of developmentassociated genes via binding to regulatory elements in the DNA in order to regulate cellular proliferation, migration, and differentiation toward normal organogenesis and body axis patterning $(35,36)$. HOX proteins are essential for normal neuronal differentiation (37) and spinal cord formation (38), while others play key roles in the development of the gut (39), ear and hindbrain (40), limbs and vertebrae (41), skin (42), lungs (43), pancreas (44), reproductive organs (45) and vasculature (46). Moreover, HOX genes are necessary for normal hematopoietic development and differentiation, and are actively expressed in primary human stem/progenitor cells $(47,48)$. 


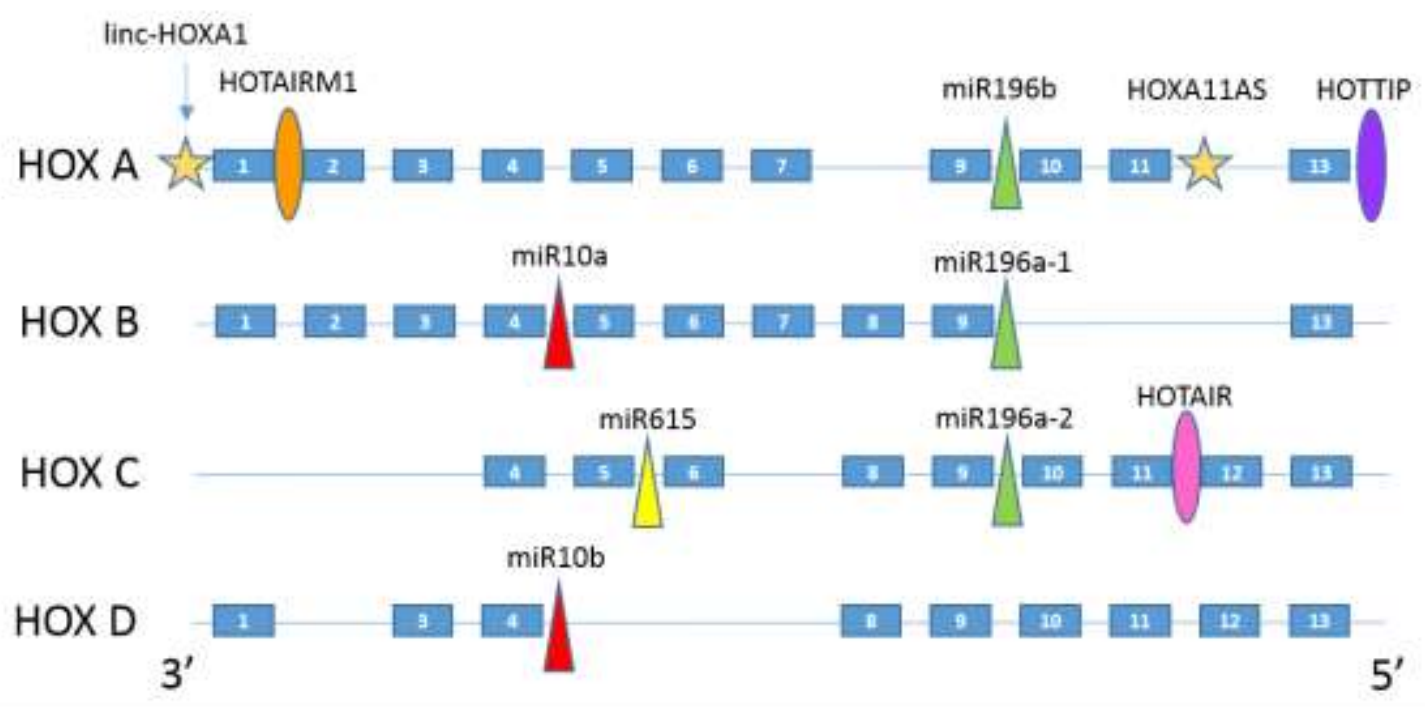

Figure 2. Schematic diagram of non-coding RNAs at their location within the HOX clusters. The HOX genes are shown as in Figure 1. A number of non-coding RNAs (both long and short) have been identified within the HOX clusters including micro-RNA families miR-196 (a-1, a-2 and b), and miR10 ( $a$ and b) and also miR615. Some have been shown to target genes within the HOX loci: miR10a targets HOXA1, HOXA3, HOXD10, miR10b targets HOXA1, HOXA3, HOXA11, HOXB3, HOXD10 and miR196b targets HOXB8. The long non-coding RNAs are linc-HOXA1 (which targets HOXA1), HOTAIR (HOX transcript antisense RNA: silences some HOXD genes), HOTAIRM1 (HOX antisense intergenic RNA myeloid 1), HOXA11AS (HOXA11 anti-sense: targets HOXA11), HOTTIP (HOXA Distal Transcript Antisense RNA: targets HOXA13). 
Regulatory roles of HOX genes are not restricted to embryonic pattering since many of them are not only found to be detectable in embryonic tissues, but also in adult tissue in an organ-specific and collinear pattern of expression comparable to that of the developing embryo $(49,50)$. In particular, adult tissues with ongoing cell differentiation are often found to retain high expression of some $H O X$ genes, for example HOXA9, HOXA10, HOXA11, and HOXA13 expression in the male and female reproductive tracts helps to regulate spermatogenesis and endometrial remodelling $(51,52)$. Another example is hematopoietic stem cells, in which different combinations of HOX genes determine lineage identity and regulate cell proliferation (53). Furthermore, HOX genes are important players in some physiological processes such as wound healing (54), and lactation (55).

\section{HOX genes and cancer}

Alterations in a number of HOX genes have been demonstrated in numerous types of cancer, but there is debate in the literature as to whether these are the cause or the effect of the malignant changes (56). An important point to note is that some members of the HOX gene family that have a pro-oncogenic role in one particular cancer may act as tumour suppressors in another cancer (56). A number of reasons for this have been suggested, including the presence or absence of some cofactors, in addition to variations in active pathways in different types of tissues (57). Moreover, such paradoxical observations support the concept that HOX gene activation and targets are cell and tissue type-specific. The underlying molecular mechanisms and the impact of abnormal HOX expression on the molecular pathology of different cancers remain elusive. However, the overall paradigm is that down-regulation or up-regulation of HOX genes lead to activation of embryonic developmental pathways in mature organs, thereby interrupting normal differentiation or cell growth pathways which in turn may contribute in abnormal cell behaviour and neoplasia $(58,59)$. In this regard, it is striking that the majority of up-regulated HOX genes in a cancer of a particular part of the body are normally expressed during development of that part, while the ones that are expressed normally in mature organs are down-regulated in cancer (56). Involvement of development-associated genes, such as HOX genes, in cancer gave rise to the "oncology recapitulates ontology" hypothesis $(60,61)$, which postulates that genes which determine the differentiation and lineage of the progenitor cells have important roles in cancer initiation. In general, abnormal changes in HOX gene expression have been found in a wide range of tumours and cancers, including leukaemia, breast cancer, prostate cancer, lung cancer and head and neck cancer (62-75). Selected findings are summarised in Table 1.

The importance of HOX genes in cancer biology is tightly linked to their capacity to regulate important mechanisms, such as angiogenesis, survival and apoptosis, cell proliferation, invasion, and 


\begin{tabular}{|l|l|l|l|}
\hline Cancer & Changes in HOX genes reported & Clinical significance & References \\
\hline Leukaemia & $\begin{array}{l}\text { Alterations mostly in A and B } \\
\text { Cluster: HOXA9, HOXA10 } \\
\text { overexpression, HOXA4, HOXA5 } \\
\text { inactivation }\end{array}$ & $\begin{array}{l}\text { High expression of HOXA9 } \\
\text { linked to poor prognosis in } \\
\text { AML }\end{array}$ & $65-67$ \\
\hline Breast & $\begin{array}{l}\text { HOXA1, A7, A5, and B7, expression, } \\
\text { loss of HOXA9 and HOXD10 }\end{array}$ & $\begin{array}{l}\text { HOXB7 may confer } \\
\text { chemotherapy resistance }\end{array}$ & $68-71$ \\
\hline Prostate & $\begin{array}{l}\text { Reduced HOXB13 and HOXD10. } \\
\text { Varies by androgen dependency. }\end{array}$ & $\begin{array}{l}\text { HOXC6 and HOXC8 may } \\
\text { predict progression }\end{array}$ & $72-75$ \\
\hline Lung & $\begin{array}{l}\text { HOXA5 HOXA7, HOXA9 HOXA10 and } \\
\text { HOXB9 expression in NSCLC and } \\
\text { SCLC, but some variation reported }\end{array}$ & $\begin{array}{l}\text { HOXA5 in SCLC linked to } \\
\text { chemotherapy resistance }\end{array}$ & $76-78$ \\
\hline
\end{tabular}

Table 1. Reported alterations in HOX gene expression in selected non-HNSCC cancers, demonstrating the wide range of HOX genes affected, some of which have proven clinical significance. 


\begin{tabular}{|l|l|l|l|l|}
\hline $\begin{array}{l}\text { HOX } \\
\text { gene }\end{array}$ & Source material & Alteration & Effect & Ref. \\
\hline HOXA1 & $\begin{array}{l}\text { Oral cavity: tissues } \\
\text { and cells }\end{array}$ & Increased expression in cancer & Promotes proliferation & 93,96 \\
\hline HOXA5 & Oral Cavity: tissues & Increased expression in cancer & Not known & 93 \\
\hline HOXA10 & $\begin{array}{l}\text { Oral cavity: cells } \\
\text { and tissues }\end{array}$ & Increased expression in cancer & Not known & 97 \\
\hline HOXB5 & Oral cavity: tissues & Increased expression in cancer & Not known & 99 \\
\hline HOXB7 & $\begin{array}{l}\text { Oral cavity: cells } \\
\text { and tissues }\end{array}$ & Increased expression in cancer & Promotes proliferation & $\begin{array}{l}30, \\
93,98\end{array}$ \\
\hline HOXB9 & $\begin{array}{l}\text { Oral cavity: cells } \\
\text { and tissues }\end{array}$ & Increased expression in cancer & $\begin{array}{l}\text { Promotes migration } \\
\text { and proliferation }\end{array}$ & 32,93 \\
\hline HOXC5 & $\begin{array}{l}\text { Tongue: animal } \\
\text { model tissues }\end{array}$ & Increased expression in cancer & Not known & 101 \\
\hline HOXC6 & $\begin{array}{l}\text { Oral cavity: tissues } \\
\text { Increased expression in cancer }\end{array}$ & $\begin{array}{l}\text { Associated with lymph } \\
\text { node metastasis }\end{array}$ & 93 \\
\hline HOXD10 & $\begin{array}{l}\text { Oral cavity: cells } \\
\text { and tissues }\end{array}$ & $\begin{array}{l}\text { High expression in primary } \\
\text { tumour, reduced in metastases }\end{array}$ & $\begin{array}{l}\text { Promotes proliferation } \\
\text { and migration }\end{array}$ & $\begin{array}{l}36, \\
103\end{array}$ \\
\hline
\end{tabular}

Table 2. The effects of alterations in HOX genes reported in HNSCC, with the source of the material used to generate the data. 
metastasis (56). Given the involvement of HOX genes in such a wide range of developmental processes, it is unsurprising that they are also important in pro-tumourigenic processes, although their role in oncogenesis varies between cell and tumour types: thus, the context in which the altered expression occurs is crucial.

HOX genes promote terminal differentiation in some tumours, whilst conversely in others the expression of certain HOX genes is associated with the loss of terminal differentiation. For example, neuroblastoma cultures differentiate in the presence of various agents, such as retinoic acid and 5bromo-2'-deoxyuridine, which may be due to the upregulation of specific HOX genes $(76,77)$. Contrastingly, overexpression of HOXC8 in prostate cancer cell lines is associated with loss of differentiation, and therefore promotes an oncogenic phenotype (70).

HOX genes also play important roles in cellular proliferation, and the overexpression of a number of HOXA and HOXB genes, including HOXA9, can promote the proliferation of haemopoietic stem cells in leukaemia (78). Upregulation of HOXA9 has been associated with the increased expression of insulin-like growth factor 1 receptor (IGF1R), which will increase autocrine stimulation (79).

HOX genes are directly involved with apoptotic pathways. HOXA5, in particular, has been linked with p53, as HOXA5 protein binds to the promoter region of TP53 to induce expression and subsequent p53-mediated apoptosis (80). Similarly, HOXA10 increases p53 expression in breast cancer cell lines (81). HOXA5 can also directly trigger apoptosis in breast cancer cells through the induction of caspases 2 and 8 (82). Conversely, HOX genes can, in some contexts, suppress apoptosis. This has been shown in non-small-cell lung cancer and some cases of melanoma $(83,84)$, where prevention of HOX-PBX dimerisation has resulted in increased apoptosis.

HOX genes have also been linked with Epithelial-Mesenchymal Transition (EMT) and invasion, and this is often associated with upregulation of HOX genes that are otherwise expressed at very low levels. For example, HOXB7 is overexpressed in breast cancer in both bone metastases and primary tumours. Cell line studies have shown that over-expression of HOXB7 can result in a metastatic phenotype, such as loss of adhesion and a number of morphological changes (85). Likewise, HOXB13 overexpression has been linked with cell invasiveness, proliferation and tamoxifen resistance in breast cancer (85).

\section{HOX genes in head and neck cancer}

Over the last decade, the role of HOX genes in the development of HNSCC has been investigated by a number of research groups. These reports include the identification of groups of over-expressed HOX genes in a number of array-based HNSCC studies where normal oral mucosa and HNSCC were 
compared (86-88). In these analyses, there are some alterations in HOX gene expression in common, but none of the findings are in complete agreement, as is often that case in array-based studies. Nevertheless, HOX genes do not rank highly in the majority of HNSCC transcriptome studies (including meta-analyses of such data: (89)). This might relate to a number of methodological factors including sample selection, methods of analysis and design of probesets.

The first complete expression profile of all 39 HOX genes in tissue samples of HNSCC, oral dysplasia and normal mucosa demonstrated that 18 of the 39 HOX genes had significantly increased expression in HNSCC when compared to normal tissues (90). The overexpressed genes were HOXA1, $A 2, A 3, A 5, A 9, B 3, B 6, B 7, B 9, C 4, C 6, C 8, C 9, C 11, C 13, D 9, D 10$ and D11. It should be noted that out of these 18 HOX genes, 11 were adjacent on the same cluster, which could indicate that HOX deregulation is controlled by common upstream regulators. Our HOX expression profile in normal, oral premalignant (OPML) and HNSCC cells showed that most of the HOX genes were more highly expressed in HNSCC cells compared to normal oral keratinocytes, some by 2-4 orders of magnitude (32). The differential expression was most marked for HOXA4, HOXA5, HOXA9, HOXB9, HOXC9 and HOXD10. The expression of some HOX genes (B1, B8, C11, D3, D4, D11 and D12) was higher in normal oral epithelial cells than in oral cancer cells but, in general, these were expressed at a very low level. Rodini and co-workers identified 5 HOX genes that were overexpressed in HNSCC; these were HOXA5, A6, C9, D10 and D11 (91). From these, HOXA5, D10 and D11 were most highly expressed. Further investigation of these genes showed that high expression level of HOXA5 was associated with favourable prognosis; patients with high HOXA5 expression had an $83.3 \%$ survival rate, compared to $43 \%$ in patients who showed comparatively lower HOXA5 expression. No such pattern was apparent for HOXD10 or HOXD11. Similar to its role in breast cancer, HOXA5 in HNSCC may act downstream of retinoic acid receptor, RARb, to promote retinoid-induced apoptosis and reduce cell survival (91). Thus overall screens of HOX gene expression in HNSCC have yielded overlapping patterns of alterations of HOX gene expression with some variation. This may be related to the type of analysis used, with those conducted in tissues reporting the closest patterns of expression.

HOX expression in HNSCC has also been compared in samples from patients with or without lymph node metastases. This revealed that expression of HOXC5, $\mathrm{C} 6$ and $\mathrm{C} 8$ were increased in the samples that had metastasised (90). Similar findings have also been presented in prostate cancer, showing that HOXC4-6 were overexpressed in lymph node metastases compared to cancers from other sites and that human prostate cancer cell lines undergo apoptosis when small interfering RNAs (siRNAs) are used to inhibit HOXC6 expression (92). It may therefore be the case that this region of the HOXC cluster is associated with a progressive cancer phenotype in both prostate cancer and HNSCC. 
The HOX genes which have been individually investigated in HNSCC are summarised in Table 2, and are grouped according to the various clusters below.

\section{HOXA cluster}

HOXA1 acts to increase cell proliferation as overexpression promoted proliferation and knock-down decreased proliferation of oral epithelial cells (93). Further investigation into other characteristics, such as apoptosis, adhesion, invasion and EMT markers found that HOXA1 did not have a significant effect, however HOXA1 overexpression was associated with lymph node metastasis and a lower overall survival rate. This finding in particular indicates that HOXA1 may have potential as a prognostic marker (93).

HOXA10 expression has also been studied In HNSCC by Yamatoji and co-workers (94). Their findings suggest that HOXA1O is overexpressed in HNSCC and associated with cancer stage, implying that its up-regulation may result in a disease progression. Furthermore, it was evident that HOXA1O expression was related to survival. These results suggest that HOXA1O could be used as a diagnostic and prognostic biomarker.

\section{HOXB cluster}

Normal oral tissues generally do not express HOXB cluster genes, whereas HNSCC cells showed relatively high expression of HOXB2, HOXB5, HOXB7 and HOXB13 $(95,96)$. HOXB7 is an important mediator of proliferation during development, and has been previously implicated to have a prooncogenic role in breast cancer and melanoma (95). Further experimentation showed that HOXB7 overexpression was associated with proliferation of oral epithelial cells mediated by fibroblast growth factor (FGF). This has also been related to clinical behaviour, where a greater proportion of HOXB7-positive cells was associated with an aggressive cancer phenotype and lower survival rates.

Our recent study demonstrated overexpression of HOXB9 in HNSCC (32). HOXB9 is expressed early in embryogenesis, and overexpression has previously been implicated in breast cancer development (97). miRNA-196a, which is also highly expressed in HNSCC, is located immediately 5' of HOXB9 on chromosome 17 (Figure 2), suggesting that HOXB9 and miRNA-196a could be co-regulated or expressed on a single polycistronic transcript. Reducing HOXB9 expression in HNSCC cells decreased cell proliferation, migration and invasion (32).

\section{HOXC cluster}

Increased expression of $\mathrm{HOXC5}$ has been correlated with proliferation and it is over-expressed in dysplastic and malignant cells in and oral carcinogenesis model (98). Interestingly, HOXC5 expression was significantly higher in dysplastic lesions, as opposed to hyperplastic lesions, and the authors 
suggest that HOXC5 may serve as a useful early diagnosis biomarker to distinguish between hyperplastic and dysplastic lesions. This has considerable prognostic significance, as the majority of hyperplastic lesions do not progress to HNSCC (98). The same authors have reported overexpression of HOXC6 in HNSCC tissues and cell lines, in which it regulated bcl-2 and was responsible for resistance to apoptosis (99).

\section{HOXD cluster}

HOXD10 is overexpressed in some HNSCC cells, and some cell lines derived from OPMLs. This pattern was also seen in tissues, and HOXD10 expression is reduced in cells from lymph node metastases, compared with their paired primary tumours $(100,101)$. When HOXD10 expression was increased in low-expressing OPL and metastatic cells, there was a resultant increase in proliferation, migration and adhesion, but a decrease in invasion. Conversely, when HOXD10 was knocked down in highexpressing HNSCC and OPML cells, this caused a decrease in proliferation, migration and adhesion, but an increase in invasion. This indicates that HOXD10 may primarily be associated with development of the primary tumour, and that expression decreases as the cancer metastases. In fact, similar patterns of HOXD10 expression have also been observed in bladder cancer (102) and breast cancer (103), however, as mentioned earlier, the functions of HOX genes are cell-specific so this may not be the case for all cancer types. The underlying mechanism for the down-regulation of HOXD10 in HNSCC metastasis is unknown at present. Two novel targets of HOXD10 were also identified. miR-146a is an inhibiter of proliferation and is down-regulated by HOXD10, whilst AMOTp80 expression is promoted by HOXD10 and is associated with increased proliferation (100).

The mechanism of this widespread dysregulation of HOX genes in HNSCC has not been clearly established. The alterations in promoter methylation and histone modifications mentioned earlier play a role $(28,30)$, as do changes in microRNA expression, such as miR-196 $(32,104)$, and other transcription factors, such as POU2F1 (101). There are numerous reports of more widespread effects of alterations in the expression of miRNAs and lincRNAs encoded within the HOX gene cluster. Recently, both miR1Ob and HOTAIR have been implicated in the control of expression of E-cadherin and as such may have roles in the epithelial-mesenchymal transition in HNSCC (105). We have previously demonstrated in HNSCC that miR-196a inhibits HOXC8 expression (32), but, unlike that seen in breast cancer, miR-10b does not regulate HOXD10 in HNSCC (100).

The existence of HOX genes in clusters makes them particularly sensitive to changes in chromosomal organization, and activators of HOX transcription include genes that mediate this process, most notably the KMT2 (previously referred to as MLL) family of methyltransferases. KMT2 genes are amongst the most highly mutated in cancer, and have been shown to have oncogenic functions in a 
wide range of solid malignancies including head and neck cancer $(106,107)$. These regulators also have crucial roles in normal development and haematopoiesis through the regulation of HOX genes. A number of studies demonstrated that KMT2-deficient embryonic bodies and conditional knockout mice showed a greatly reduced expression of a number of HOX genes including HOXA7, HOXA9 and HOXA10 as well as other HOXB and HOXC genes $(108,109)$.

\section{The clinical utility of HOX genes in cancer}

Given the high degree of HOX gene dysregulation seen in cancer, including very high expression of some in tissues, this raises the possibility of using HOX genes as biomarkers or targets for therapeutic intervention. Much work remains to be done before HOX genes could be utilised as biomarkers: and although changes in HOX expression have been linked with poor outcome in HNSCC $(94,110)$, it remains unclear how these alterations contribute to the natural history and clinical progression of HNSSC.

HOX genes do have potential advantages as therapeutic targets: the tumours arise in adult tissues, many of which no longer express HOX genes to any significant extent, which could confer a level of specificity not seen in other targeted therapies such as anti-EGFR therapy. However, the fact that similar/paralogous HOX genes often have overlapping functions makes it difficult to evaluate the effects of targeting individual genes and, indeed, to target specific genes. Indeed, it is likely that inhibition of all the genes within a particular paralogous group will be required. As an alternative approach, Morgan and co-workers developed the novel cell-permeable 18-amino acid peptide, HXR9, which competitively binds PBX by mimicking the hexapeptide sequence found in the HOX homeodomain, thus preventing many HOX-PBX interactions and repressing overall HOX gene function (111). HOX/PBX dimers have significantly greater binding affinity and specificity for target DNA sequences than the HOX monomer alone (112).

The effects of this peptide have been investigated in melanoma (111), non-small-cell lung cancer (NSCLC) (113) and prostate cancer (114). In all three of these studies, HXR9 resulted in increased apoptosis of cancer cell lines, believed to be partially due to increased translation of cFos. cFos has been previously shown to repress c-FLIP(L), a gene with anti-apoptotic functions, thus sensitising cancer cells to apoptosis (115). For NSCLC cells, exposure to HXR9 was also associated with an increase in expression of the early growth response 1 (EGR1) gene, which is known to prevent angiogenesis and tumour invasion while promoting apoptosis (113). Prostate cancer cell lines, which showed dysregulated HOX expression, were more sensitive to HXR9-induced cell death than a cell line derived from normal tissue (116). The effects of HXR9 in vivo were compared to a control peptide, CXR9, which does not have a functional hexapeptide sequence, by injection into murine 
models of prostate cancer. After 52 days the tumours treated with CXR9 had increased size by 8 fold, compared to a 1.5 fold increase for the HXR9-treated tumours. Histological examination found that CXR9-treated tumours were composed mainly of undifferentiated cells, whereas the HXR9-treated tumours had relatively few cells and were composed mainly of cellular debris (116). A similar method was used to investigate NSCLC and melanoma, with similar results of reduced tumour growth and increased cell death. Given this data in a number of tumour types, there is a substantial body of evidence that targeting HOX-PBX interactions could pose a viable therapeutic strategy. We are currently evaluating these effects of these peptides in HNSCC cells

There are, however, a number of limitations to this approach. These include lack of specificity and the observation that 5' HOX genes, many of which are highly expressed in cancer, are less PBX dependant. Some of these may be more dependent on MEIS as a cofactor. Other possible approaches include the introduction of HOX-specific siRNA or shRNA capable of reducing the expression of cancer-promoting HOX genes or by the re-expression of tumour suppressing HOX genes. This method has been successful in previous studies, where re-introduction of HOXD10 suppressed the growth and progression of metastatic breast cancer cells (117).

\section{Conclusion}

It is clear that HOX genes play an important role in the oncogenesis and metastasis in many cancers, including HNSCC. Genes of specific note have been discussed, however targeting individual HOX genes may not be a viable therapeutic option due to the functional redundancy of many HOX members. There are a number of outstanding questions which require an answer before their potential can be fully assessed, however their dysregulation in this malignancy suggests that they could act as key prognostic and diagnostic markers, as well as therapeutic targets. However, further study is necessary before the clinical utility of this approach can be established and we are currently pursuing a number of these outstanding issues in an attempt to understand the biology and clinical utility of HOX genes in HNSCC. 


\section{References}

1. BATESON W. Materials for the study of variation, treated with especial regard to discontinuity in the origin of species. MacMillan: London, 1894.

2. LEWIS EB A gene complex controlling segmentation in Drosophila. Nature 1978; 276: 565-70.

3. KAUFMAN TC, LEWIS R, WAKIMOTO B Cytogenetic Analysis of Chromosome 3 in DROSOPHILA MELANOGASTER: The Homoeotic Gene Complex in Polytene Chromosome Interval 84a-B. Genetics 1980; 94: 115-33.

4. LEVINE M, HOEY T Homeobox Proteins as Sequence-Specific Transcription Factors. Cell 1988; 55: 537-540.

5. LIANG ZC, BIGGIN MD Eve and ftz regulate a wide array of genes in blastoderm embryos: the selector homeoproteins directly or indirectly regulate most genes in Drosophila.

Development 1998; 125: 4471-4482.

6. MCGINNIS W, GARBER RL, WIRZ J et al. A Homologous Protein-Coding Sequence in Drosophila Homeotic Genes and Its Conservation in Other Metazoans. Cell 1984; 37: 403408.

7. AKAM M Hox and Hom - Homologous Gene Clusters in Insects and Vertebrates. Cell 1989; 57: 347-349.

8. HOMBRIA JCG, LOVEGROVE B Beyond homeosis - HOX function in morphogenesis and organogenesis. Differentiation 2003; 71: 461-476.

9. HOLLAND PWH, BOOTH HAF, BRUFORD EA Classification and nomenclature of all human homeobox genes. Bmc Biol 2007; 5.

10. SCOTT MP Vertebrate Homeobox Gene Nomenclature. Cell 1992; 71: 551-553.

11. APIOU F, FLAGIELLO D, CILLO $C$ et al. Fine mapping of human HOX gene clusters. Cytogenetics and Cell Genetics 1996; 73: 114-115.

12. MANN RS, CHAN SK Extra specificity from extradenticle: The partnership between HOX and PBX/EXD homeodomain proteins. Trends in Genetics 1996; 12: 258-262.

13. SHANMUGAM K, GREEN NC, RAMBALDI I et al. PBX and MEIS as non-DNA-binding partners in trimeric complexes with HOX proteins. Molecular and Cellular Biology 1999; 19: 75777588.

14. SHANMUGAM K, FEATHERSTONE MS, SARAGOVI HU Residues flanking the HOX YPWM motif contribute to cooperative interactions with PBX. Journal of Biological Chemistry 1997; 272: 19081-19087.

15. LARONDE-LEBLANC NA, WOLBERGER C Structure of HoxA9 and Pbx1 bound to DNA: Hox hexapeptide and DNA recognition anterior to posterior. Gene Dev 2003; 17: 2060-2072.

16. MCINTYRE DC, RAKSHIT S, YALLOWITZ AR et al. Hox patterning of the vertebrate rib cage. Development 2007; 134: 2981-2989.

17. DUBOULE D Temporal Colinearity and the Phylotypic Progression - a Basis for the Stability of a Vertebrate Bauplan and the Evolution of Morphologies through Heterochrony.

Development 1994: 135-142.

18. DUBOULE D, MORATA G Colinearity and Functional Hierarchy among Genes of the Homeotic Complexes. Trends in Genetics 1994; 10: 358-364.

19. VASANTHI D, MISHRA RK Epigenetic regulation of genes during development: a conserved theme from flies to mammals. Journal of genetics and genomics = Yi chuan xue bao 2008; 35: 413-29.

20. SOSHNIKOVA N, DUBOULE D Epigenetic regulation of vertebrate Hox genes: a dynamic equilibrium. Epigenetics 2009; 4: 537-40.

21. DUESTER G Retinoic acid synthesis and signaling during early organogenesis. Cell 2008; 134 : 921-31.

22. DAFTARY GS, TAYLOR HS Endocrine regulation of HOX genes. Endocrine reviews 2006; 27: 331-55. 
23. BONCINELLI E, SIMEONE A, ACAMPORA D et al. HOX gene activation by retinoic acid. Trends Genet 1991; 7: 329-34.

24. MARSHALL H, MORRISON A, STUDER M et al. Retinoids and Hox genes. FASEB J 1996; 10: 969-78.

25. TABIN C The initiation of the limb bud: growth factors, Hox genes, and retinoids. Cell 1995; 80: 671-4.

26. SOSHNIKOVA N, DUBOULE D Epigenetic regulation of Hox gene activation: the waltz of methyls. Bioessays 2008; 30: 199-202.

27. BARBER BA, RASTEGAR M Epigenetic control of Hox genes during neurogenesis, development, and disease. Annals of anatomy = Anatomischer Anzeiger : official organ of the Anatomische Gesellschaft 2010; 192: 261-74.

28. MARCINKIEWICZ KM, GUDAS LJ Altered histone mark deposition and DNA methylation at homeobox genes in human oral squamous cell carcinoma. J Cell Physiol 2014; 229: 1405-16.

29. XAVIER FC, DESTRO MF, DUARTE CM et al. Epigenetic repression of HOXB cluster in oral cancer cell lines. Arch Oral Biol 2014; 59: 783-9.

30. MARCINKIEWICZ KM, GUDAS LJ Altered epigenetic regulation of homeobox genes in human oral squamous cell carcinoma cells. Exp Cell Res 2014; 320: 128-43.

31. MA L, REINHARDT F, PAN E et al. Therapeutic silencing of miR-10b inhibits metastasis in a mouse mammary tumor model. Nat Biotechnol 2010; 28: 341-7.

32. DARDA L, HAKAMI F, MORGAN R et al. The Role of HOXB9 and miR-196a in Head and Neck Squamous Cell Carcinoma. PLoS One 2015; 10: e0122285.

33. LIU CJ, TSAI MM, TU HF et al. miR-196a overexpression and miR-196a2 gene polymorphism are prognostic predictors of oral carcinomas. Ann Surg Oncol 2013; 20 Suppl 3: S406-14.

34. NAKAYAMA I, SHIBAZAKI M, YASHIMA-ABO A et al. Loss of HOXD10 expression induced by upregulation of miR-10b accelerates the migration and invasion activities of ovarian cancer cells. Int J Oncol 2013; 43: 63-71.

35. KRUMLAUF R Hox genes in vertebrate development. Cell 1994; 78: 191-201.

36. DORN A, AFFOLTER M, GEHRING WJ et al. Homeodomain proteins in development and therapy. Pharmacology \& therapeutics 1994; 61: 155-84.

37. GAUFO GO, THOMAS KR, CAPECCHI MR Hox3 genes coordinate mechanisms of genetic suppression and activation in the generation of branchial and somatic motoneurons. Development 2003; 130: 5191-201.

38. CARPENTER EM, GODDARD JM, DAVIS AP et al. Targeted disruption of Hoxd-10 affects mouse hindlimb development. Development 1997; 124: 4505-14.

39. BECK F Homeobox genes in gut development. Gut 2002; 51: 450-4.

40. CHISAKA O, MUSCI TS, CAPECCHI MR Developmental defects of the ear, cranial nerves and hindbrain resulting from targeted disruption of the mouse homeobox gene Hox-1.6. Nature 1992; 355: 516-20.

41. HORAN GS, RAMIREZ-SOLIS R, FEATHERSTONE MS et al. Compound mutants for the paralogous hoxa-4, hoxb-4, and hoxd-4 genes show more complete homeotic transformations and a dose-dependent increase in the number of vertebrae transformed. Genes Dev 1995; 9: 1667-77.

42. STELNICKI EJ, KOMUVES LG, KWONG AO et al. HOX homeobox genes exhibit spatial and temporal changes in expression during human skin development. J Invest Dermatol 1998; 110: $110-5$.

43. GOLPON HA, GERACI MW, MOORE MD et al. HOX genes in human lung: altered expression in primary pulmonary hypertension and emphysema. Am J Pathol 2001; 158: 955-66.

44. GRAY S, PANDHA HS, MICHAEL $A$ et al. HOX genes in pancreatic development and cancer. Jop 2011; 12: 216-9.

45. DU H, TAYLOR HS Molecular regulation of mullerian development by Hox genes. Ann N Y Acad Sci 2004; 1034: 152-65. 
46. GORSKI DH, WALSH K Control of vascular cell differentiation by homeobox transcription factors. Trends Cardiovasc Med 2003; 13: 213-20.

47. SAUVAGEAU G, LANSDORP PM, EAVES CJ et al. Differential expression of homeobox genes in functionally distinct CD34+ subpopulations of human bone marrow cells. Proc Natl Acad Sci U S A 1994; 91: 12223-7.

48. MAGLI MC, LARGMAN C, LAWRENCE HJ Effects of HOX homeobox genes in blood cell differentiation. J Cell Physiol 1997; 173: 168-77.

49. NEVILLE SE, BAIGENT SM, BICKNELL AB et al. Hox gene expression in adult tissues with particular reference to the adrenal gland. Endocrine research 2002; 28: 669-73.

50. YAMAMOTO M, TAKAI D, YAMAMOTO $\mathrm{F}$ et al. Comprehensive expression profiling of highly homologous 39 hox genes in 26 different human adult tissues by the modified systematic multiplex RT-pCR method reveals tissue-specific expression pattern that suggests an important role of chromosomal structure in the regulation of hox gene expression in adult tissues. Gene expression 2003; 11: 199-210.

51. TAYLOR HS The role of HOX genes in the development and function of the female reproductive tract. Seminars in reproductive medicine 2000; 18: 81-9.

52. LINDSEY S, WILKINSON MF Homeobox genes and male reproductive development. Journal of assisted reproduction and genetics 1996; 13: 182-92.

53. EKLUND EA The role of HOX genes in malignant myeloid disease. Current opinion in hematology 2007; 14: 85-9.

54. MACK JA, ABRAMSON SR, BEN Y et al. Hoxb13 knockout adult skin exhibits high levels of hyaluronan and enhanced wound healing. FASEB J 2003; 17: 1352-4.

55. MORGAN R Hox genes: a continuation of embryonic patterning? Trends Genet 2006; 22: 679.

56. ABATE-SHEN C Deregulated homeobox gene expression in cancer: cause or consequence? Nat Rev Cancer 2002; 2: 777-85.

57. SALEH M, RAMBALDI I, YANG XJ et al. Cell signaling switches HOX-PBX complexes from repressors to activators of transcription mediated by histone deacetylases and histone acetyltransferases. Mol Cell Biol 2000; 20: 8623-33.

58. LAWRENCE HJ, LARGMAN C Homeobox genes in normal hematopoiesis and leukemia. Blood 1992; 80: 2445-53.

59. SHAH N, SUKUMAR S The Hox genes and their roles in oncogenesis. Nature Reviews Cancer 2010; 10: 361-371.

60. LECHNER JF, WANG Y, SIDDIQ F et al. Human lung cancer cells and tissues partially recapitulate the homeobox gene expression profile of embryonic lung. Lung Cancer 2002; 37: 41-7.

61. LAPPIN TR, GRIER DG, THOMPSON A et al. HOX genes: seductive science, mysterious mechanisms. Ulster Med J 2006; 75: 23-31.

62. THORSTEINSDOTTIR U, SAUVAGEAU G, HOUGH MR et al. Overexpression of HOXA10 in murine hematopoietic cells perturbs both myeloid and lymphoid differentiation and leads to acute myeloid leukemia. Molecular and Cellular Biology 1997; 17: 495-505.

63. KROON E, KROSL J, THORSTEINSDOTTIR U et al. Hoxa9 transforms primary bone marrow cells through specific collaboration with Meis1a but not Pbx1b. Embo Journal 1998; 17: 37143725 .

64. STRATHDEE G, HOLYOAKE TL, SIM A et al. Inactivation of HOXA genes by hypermethylation in myeloid and lymphoid malignancy is frequent and associated with poor prognosis. Clin Cancer Res 2007; 13: 5048-55.

65. CHARIOT A, CASTRONOVO V Detection of HOXA1 expression in human breast cancer. Biochem Biophys Res Commun 1996; 222: 292-7.

66. CHARIOT A, MOREAU L, SENTERRE $G$ et al. Retinoic acid induces three newly cloned HOXA1 transcripts in MCF7 breast cancer cells. Biochem Biophys Res Commun 1995; 215: 713-20. 
67. CARE A, SILVANI A, MECCIA E et al. Transduction of the SkBr3 breast carcinoma cell line with the HOXB7 gene induces bFGF expression, increases cell proliferation and reduces growth factor dependence. Oncogene 1998; 16: 3285-9.

68. JIN K, KONG XJ, SHAH T et al. The HOXB7 protein renders breast cancer cells resistant to tamoxifen through activation of the EGFR pathway. Proceedings of the National Academy of Sciences of the United States of America 2012; 109: 2736-2741.

69. KIM SD, PARK RY, KIM YR et al. HOXB13 is co-localized with androgen receptor to suppress androgen-stimulated prostate-specific antigen expression. Anatomy \& cell biology 2010; 43: 284-93.

70. WALTREGNY D, ALAMI Y, CLAUSSE N et al. Overexpression of the homeobox gene HOXC8 in human prostate cancer correlates with loss of tumor differentiation. Prostate 2002; 50: 1629.

71. MCCABE CD, SPYROPOULOS DD, MARTIN D et al. Genome-wide analysis of the homeobox C6 transcriptional network in prostate cancer. Cancer Res 2008; 68: 1988-96.

72. MILLER GJ, MILLER HL, VAN BOKHOVEN A et al. Aberrant HOXC expression accompanies the malignant phenotype in human prostate. Cancer Res 2003; 63: 5879-88.

73. ABE M, HAMADA J, TAKAHASHI O et al. Disordered expression of HOX genes in human nonsmall cell lung cancer. Oncol Rep 2006; 15: 797-802.

74. CALVO R, WEST J, FRANKLIN W et al. Altered HOX and WNT7A expression in human lung cancer. Proc Natl Acad Sci U S A 2000; 97: 12776-81.

75. XIAO F, CHEN Z, ZENG X et al. [Role of homeobox gene A5 in multidrug resistance of human small cell lung cancer cells]. Nan Fang Yi Ke Da Xue Xue Bao 2013; 33: 1665-8.

76. MANOHAR CF, SALWEN HR, FURTADO MR et al. Up-regulation of HOXC6, HOXD1, and HOXD8 homeobox gene expression in human neuroblastoma cells following chemical induction of differentiation. Tumour Biol 1996; 17: 34-47.

77. ZHANG X, HAMADA J, NISHIMOTO A et al. HOXC6 and HOXC11 increase transcription of S100beta gene in BrdU-induced in vitro differentiation of GOTO neuroblastoma cells into Schwannian cells. J Cell Mol Med 2007; 11: 299-306.

78. DICKSON GJ, KWASNIEWSKA A, MILLS KI et al. Hoxa6 potentiates short-term hemopoietic cell proliferation and extended self-renewal. Exp Hematol 2009; 37: 322-33 e3.

79. WHELAN JT, LUDWIG DL, BERTRAND FE HoxA9 induces insulin-like growth factor-1 receptor expression in B-lineage acute lymphoblastic leukemia. Leukemia 2008; 22: 1161-9.

80. RAMAN V, MARTENSEN SA, REISMAN D et al. Compromised HOXA5 function can limit p53 expression in human breast tumours. Nature 2000; 405: 974-978.

81. CHU MC, SELAM FB, TAYLOR HS HOXA10 regulates $p 53$ expression and matrigel invasion in human breast cancer cells. Cancer Biology \& Therapy 2004; 3: 568-572.

82. CHEN HX, CHUNG S, SUKUMAR S HOXA5-induced apoptosis in breast cancer cells is mediated by caspases 2 and 8. Molecular and Cellular Biology 2004; 24: 924-935.

83. PLOWRIGHT L, HARRINGTON KJ, PANDHA HS et al. HOX transcription factors are potential therapeutic targets in non-small-cell lung cancer (targeting HOX genes in lung cancer). $\mathrm{Br} \mathrm{J}$ Cancer 2009; 100: 470-5.

84. ERRICO MC, FELICETTI F, BOTTERO L et al. The abrogation of the HOXB7/PBX2 complex induces apoptosis in melanoma through the miR-221\&222-C-FOS pathway. International Journal of Cancer 2013; 133: 879-892.

85. WU X, CHEN H, PARKER B et al. HOXB7, a Homeodomain Protein, Is Overexpressed in Breast Cancer and Confers Epithelial-Mesenchymal Transition (vol 66, pg 9527, 2006). Cancer Research 2015; 75: 2401-2401.

86. KURIAKOSE MA, CHEN WT, HE ZM et al. Selection and validation of differentially expressed genes in head and neck cancer. Cell Mol Life Sci 2004; 61: 1372-83. 
87. GINOS MA, PAGE GP, MICHALOWICZ BS et al. Identification of a gene expression signature associated with recurrent disease in squamous cell carcinoma of the head and neck. Cancer Res 2004; 64: 55-63.

88. THURLOW JK, PENA MURILLO CL, HUNTER KD et al. Spectral clustering of microarray data elucidates the roles of microenvironment remodeling and immune responses in survival of head and neck squamous cell carcinoma. J Clin Oncol 2010; 28: 2881-8.

89. $\mathrm{YU}$ YH, KUO HK, CHANG KW The evolving transcriptome of head and neck squamous cell carcinoma: a systematic review. PLoS One 2008; 3: e3215.

90. HASSAN N, HAMADA J, MURAI T et al. Aberrant expression of HOX genes in oral dysplasia and squamous cell carcinoma tissues. Oncol Res 2006; 16: 217-24.

91. RODINI CO, XAVIER FCA, PAIVA KBS et al. Homeobox gene expression profile indicates HOXA5 as a candidate prognostic marker in oral squamous cell carcinoma. International Journal of Oncology 2012; 40: 1180-1188.

92. ERNST T, HERGENHAHN M, KENZELMANN M et al. Decrease and gain of gene expression are equally discriminatory markers for prostate carcinoma - A gene expression analysis on total and microdissected prostate tissue. American Journal of Pathology 2002; 160: 2169-2180.

93. BITU C, DE SOUZA SETÚBAL DESTRO M, CARRERA $M$ et al. HOXA1 is overexpressed in oral squamous cell carcinomas and its expression is correlated with poor prognosis. BMC Cancer 2012; 12.

94. YAMATOJI M, KASAMATSU A, YAMANO $\mathrm{Y}$ et al. State of homeobox A10 expression as a putative prognostic marker for oral squamous cell carcinoma. Oncology Reports 2010; 23: 61-67.

95. DESTRO MFDS, BITU CC, ZECCHIN KG et al. Overexpression of HOXB7 homeobox gene in oral cancer induces cellular proliferation and is associated with poor prognosis. International Journal of Oncology 2010; 36: 141-149.

96. TUCCI R, CAMPOS MS, MATIZONKAS-ANTONIO LF et al. HOXB5 expression in oral squamous cell carcinoma. J Appl Oral Sci 2011; 19: 125-9.

97. SEKI H, HAYASHIDA T, JINNO H et al. HOXB9 expression promoting tumor cell proliferation and angiogenesis is associated with clinical outcomes in breast cancer patients. Ann Surg Oncol 2012; 19: 1831-40.

98. MOON SM, AHN MY, KWON SM et al. Homeobox C5 expression is associated with the progression of 4-nitroquinoline 1-oxide-induced rat tongue carcinogenesis. Journal of Oral Pathology \& Medicine 2012; 41: 470-476.

99. MOON SM, KIM SA, YOON JH et al. HOXC6 Is Deregulated in Human Head and Neck Squamous Cell Carcinoma and Modulates Bcl-2 Expression. Journal of Biological Chemistry 2012; 287: 35678-35688.

100. HAKAMI F, DARDA L, STAFFORD P et al. The roles of HOXD10 in the development and progression of head and neck squamous cell carcinoma (HNSCC). Br J Cancer 2014; 111: 80716.

101. SHARPE DJ, ORR KS, MORAN M et al. POU2F1 activity regulates HOXD10 and HOXD11 promoting a proliferative and invasive phenotype in head and neck cancer. Oncotarget 2014; 5: 8803-15.

102. BAFFA R, FASSAN M, VOLINIA S et al. MicroRNA expression profiling of human metastatic cancers identifies cancer gene targets. Journal of Pathology 2009; 219: 214-221.

103. MA L, TERUYA-FELDSTEIN J, WEINBURG R Tumour invasion and metastasis initiated by microRNA-10b in breast cancer. Nature 2007; 449: 682-688.

104. SEVERINO P, BRUGGEMANN H, ANDREGHETTO FM et al. MicroRNA expression profile in head and neck cancer: HOX-cluster embedded microRNA-196a and microRNA-10b dysregulation implicated in cell proliferation. BMC Cancer 2013; 13: 533. 
105. WU Y, ZHANG L, ZHANG L et al. Long non-coding RNA HOTAIR promotes tumor cell invasion and metastasis by recruiting EZH2 and repressing E-cadherin in oral squamous cell carcinoma. Int J Oncol 2015.

106. RAO RC, DOU Y Hijacked in cancer: the KMT2 (MLL) family of methyltransferases. Nat Rev Cancer 2015; 15: 334-46.

107. WEND P, FANG L, ZHU Q et al. Wnt/beta-catenin signalling induces MLL to create epigenetic changes in salivary gland tumours. EMBO J 2013; 32: 1977-89.

108. ERNST P, MABON M, DAVIDSON AJ et al. An MII-dependent Hox program drives hematopoietic progenitor expansion. Curr Biol 2004; 14: 2063-9.

109. JUDE CD, CLIMER L, XU D et al. Unique and independent roles for MLL in adult hematopoietic stem cells and progenitors. Cell Stem Cell 2007; 1: 324-37.

110. BITU CC, DESTRO MFDSS, CARRERA M et al. HOXA1 is overexpressed in oral squamous cell carcinomas and its expression is correlated with poor prognosis. BMC cancer 2012; 12: 146.

111. MORGAN R, PIRARD PM, SHEARS L et al. Antagonism of HOX/PBX dimer formation blocks the in vivo proliferation of melanoma. Cancer Res 2007; 67: 5806-13.

112. CHANG CP, SHEN WF, ROZENFELD S et al. Pbx proteins display hexapeptide-dependent cooperative DNA binding with a subset of Hox proteins. Genes Dev 1995; 9: 663-74.

113. PLOWRIGHT L, HARRINGTON K, PANDHA H et al. HOX transcription factors are potential therapeutic targets in non-small-cell lung cancer (targeting HOX genes in lung cancer). British Journal of Cancer 2009; 100: 470-475.

114. MORGAN R, BOXALL A, HARRINGTON $\mathrm{K}$ et al. Targeting HOX transcription factors in prostate cancer. BMC Urology 2014; 14: 1-9.

115. ZHANG XP, ZHANG L, YANG HM et al. c-Fos as a proapoptotic agent in TRAIL-induced apoptosis in prostate cancer cells. Cancer Research 2007; 67: 9425-9434.

116. MORGAN R, BOXALL A, HARRINGTON KJ et al. Targeting HOX transcription factors in prostate cancer. BMC urology 2014; 14: 17.

117. CARRIO M, ARDERIU G, MYERS C et al. Homeobox D10 induces phenotypic reversion of breast tumor cells in a three-dimensional culture model. Cancer Res 2005; 65: 7177-85. 